\title{
LINKING ALASKA'S PREDICTED CLIMATE, GYRFALCON, AND PTARMIGAN DISTRIBUTIONS IN SPACE AND TIME: A UNIQUE 200-YEAR PERSPECTIVE
}

\author{
Travis Booms ${ }^{1}$, Michael Lindgren², and Falk Huettmann²
}

\begin{abstract}
${ }^{1}$ Wildlife Diversity Program, Alaska Department of Fish and Game, 1300 College Road, Fairbanks, AK 99701,USA. E-mail: travis.booms@alaska.gov

${ }^{2}$ EWHALE Spatial Ecology Laboratory, Institute of Arctic Biology, Department of Biology \& Wildlife, University of Alaska Fairbanks, 419 Irving I, Fairbanks, AK 99775, USA
\end{abstract}

\begin{abstract}
Gyrfalcons (Falco rusticolus), Rock Ptarmigan (Lagopus muta), and Willow Ptarmigan (L. lagopus) are quintessential Arctic species that are closely linked within the Arctic ecosystem. They likely face similar challenges in the face of rapid changes to their Arctic climate. Gyrfalcons in particular may be most challenged by rapid climate change because of their relatively specialized ecological niche, small population size, and K-selected life history strategy. Given this situation, we were interested in predicting how the distribution of these species may change under current climate predictions. Therefore, we modeled the fundamental niche of each species in relation to temperature and precipitation in space and time across 200 years in Alaska (1900-2100). Though the realized niche will ultimately determine where species are distributed in the future, we interpreted our predictions as representing the areas in which environmental conditions will allow the species to occur. We were interested in the large-scale, climate-induced trends in expansion, contraction, and overlap of these areas over time.
\end{abstract}

We used the Scenarios Network for Alaska Planning (SNAPs) regionalized/downscaled decadal mean June and December temperature and precipitation predictions from the A1B scenario, and as proposed by the United Nations Intergovernmental Panel on Climate Change (IPCC), to forward-model distributions from 2009-2099 in 30-year intervals. We used historical temperature and precipitation measurements from 1900-2006 to backwards-model the distribution of the species' fundamental niche to qualitatively assess forward-modeling predictive accuracy.

Forward-models predicted that the fundamental niches of Gyrfalcons and ptarmigan will contract spatially, and backwards-models suggested that they have contracted in the past as Alaska's climate has warmed. Over the 200-year period, the total geographic area over which the species' fundamental niches were predicted to occur decreased overall by $20 \%$ (Willow Ptarmigan), $40 \%$ (Rock Ptarmigan) and 60\% (Gyrfalcon). The distribution of the predicted fundamental niche of each species also became more fragmented, and the percent of spatial overlap between predicted presence of Gyrfalcons and ptarmigan declined over time. These alterations may affect the species' long-term viability and co-evolution and will likely influence important biological processes such as dispersal, genetic diversity, predator-prey dynamics, and basic behavior. Predicted shifts in the geographic distribution of their fundamental niches may have cascading effects on other species, communities, and systems. For science-based, pro-active, adaptive management, 
we propose to implement findings from this model by testing them further and making spatial models and their predictions an inherent part of the management and legal procedures used to address conservation in the world of rapid Arctic climate change. Received 29 December 2011, accepted 20 June 2011.

Booms, T., M. Lindgren, And F. Huettmann. 2011. Linking Alaska's Predicted Climate, Gyrfalcon, and ptarmigan distributions in space and time: A unique 200-year perspective. Pages 177-190 in R. T. Watson, T. J. Cade, M. Fuller, G. Hunt, and E. Potapov (Eds.). Gyrfalcons and Ptarmigan in a Changing World, Volume I. The Peregrine Fund, Boise, Idaho, USA. http://dx.doi.org/ 10.4080/gpcw.2011.0116

Key words: Climate change, Falco rusticolus, modeling, niche, Arctic.

ALASKA's NATURAL HISTORY was widely driven by the glacial retreat about 11,000 years ago. From then on, Beringia spread and retreated to include what is today's Alaska. Indigenous people affected the landscape (Glavin 2000), but a larger influence was post-contact with outside groups such as the Russian colonization, the purchase of the Alaska Territory by the United States in 1867, Alaska entering statehood in 1959, and industrial changes during the last 50 years. Cumulative landscape modifications that have occurred since statehood are difficult to quantify or measure, but have had a significant effect in some respects, e.g. fragmentation, invasive species, and habitat loss (Murphy et al. 2010). Despite Alaska's reputation for being wild, the last frontier, and carrying endless and well-managed landscapes, it is clear that: a) truly pristine and untouched environments do not exist in times of man-made climate change (Turner et al. 2002; Chapin et al.2009), b) Alaska is already dealing with major conservation challenges, including land cover and land use changes, development of natural resources, invasive species, and man-made climate change (Symon et al. 2005, Hinzmann et al. 2005), c) climate change will affect Alaska to a greater extent than places of lower latitudes (Martin et al. 2009), d) the Intergovernmental Panel on Climate Change (IPCC) scenarios of future climates have been demonstrated to underestimate rates of change in some systems (Stroeve 2007), and e) the global population and Alaska's urbanization is continuing to rise. The effects of these issues are found across the state and are affecting Gyrfalcons (Falco rusticolus), their prey, and their habitats.

Biology of Gyrfalcons.-Gyrfalcons are apex predators that sit at the top of a food chain. Therefore, changes in the food chain and habitats upon which this species depends are likely to be evident in these birds. This is especially so because the species breeds only in Arctic and sub-Arctic landscapes and relies heavily on a few prey species. Across Alaska and its circumpolar distribution, the Gyrfalcon is a ptarmigan specialist. Although it can take a diversity of prey species in several combinations and fractions, in nearly all instances ptarmigan makeup the majority of the diet, especially during pair bonding and egg production (Booms et al. 2008). Hence, understanding and predicting how ptarmigan have and will adjust to landscape changes is integral to understanding, managing and predicting the response of Gyrfalcons. However, the Gyrfalcon's reliance on ptarmigan does not necessitate that their spatial distributions and abundances are linear or automatic. Buffer mechanisms and delays might exist that may blur the link and render it indirect, as documented in other systems (Watson 2010, Krebs et al. 2001).

Biology of Ptarmigan.-Little is known about ptarmigan in Alaska's landscape because the species has received little research or surveying effort in the state. The distribution and ecological niche of ptarmigan in Alaska and 
elsewhere is informed by many variables, including the distribution and availability of buds and berries, snow depth, climate, and other factors (Dublin and Taras 2005). However, most of these drivers have not been rigorously mapped in Alaska or in the circumpolar Arctic, and therefore they can only be approximated through model predictions. To our knowledge, the best published distribution maps for the two most widespread and common species in Alaska, Rock Ptarmigan (Lagopus muta) and Willow Ptarmigan (L. lagopus), are presented in their Birds of North America accounts (Hannon et al. 1998, Montgomerie and Holder 1998), even though the range maps are largely not based on quantitative data.

Fundamental Niche.-Evolution shapes species and where and how they live. The ecological niche is a fundamental concept, defining life spaces (Cushman and Huettmann 2010). The concept is well established and includes both the fundamental niche (defined by abiotic factors) and the realized niche (defined by abiotic and biotic factors) (Hutchinson 1957). The fundamental niche can be thought of as the multidimensional space in which environmental conditions allow a species to exist. This space is further restricted by biotic variables (realized niche) that ultimately dictate where a species actually occurs in time and space within the fundamental niche. Hence, it is useful to think of the fundamental niche as defining the outer bounds of where, in multi-dimensional space, a species can occur. We focused on these largescale, climate-induced, general trends in expansion, contraction, and overlap of these fundamental niches over time. When linked with multivariate techniques, advanced data mining, and model predictions, the ecological niche concept makes for a useful concept and tool to study macroecology and for sciencebased management.

It is important to note that ecological niches can change over time as species adapt to their surroundings. We have implicitly assumed, however, that the Gyrfalcon is unlikely to shift its fundamental niche significantly within the 200-year time span examined here because ecological niche adaptations are generally conserved over time (Peterson et al. 1999) and because the species is a fairly specialized, apex predator with a small population size and $\mathrm{K}$ selected life history strategies. These characteristics reduce a species' ability to adapt to rapid changes in climate as are predicted to occur in Alaska through the next century.

This assumption may be less valid for ptarmigan, which are more generalistic and are considered R-selected species. This may make them better suited to adapting to rapidly changing climate regimes. However, the ways in which they may adapt are unknown, and we are therefore left with modeling as our best, albeit imperfect, tool to predict how the species may be affected by changes in the local climate regime. Here, we modeled a simplified version of the fundamental niche of an apex predator and its primary prey across space and time in Alaska to assess how the spatial distribution of their fundamental niches may be affected by future changes in temperature and precipitation.

\section{METHODS}

The idea that predators and their prey can be modeled stems back to Lotka (1925) and others (e.g. Krebs et al. 2001). Most of the earlier models were not spatial and therefore lacked important spatial linkages needed to fully understand animal distributions on a landscape. Although these issues have improved over the past decades with increases in computing power, truly spatial models based on GIS mapping concepts that take into account many interactions, neighborhood relationships, and autocorrelations are uncommon but have recently been increasing (Cushman and Huettmann 2010, Drew et al. 2010).

Training Data.-Gyrfalcon nest locations were obtained from Booms et al. (2009) and consisted of historical nest locations gathered 


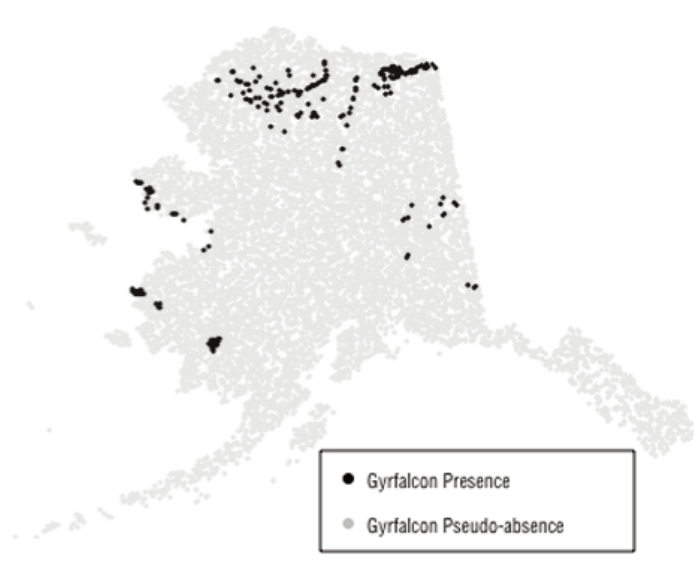

Figure 1. Distribution of Gyrfalcon presence points (historical nest sites) and random pseudoabsence points in Alaska.
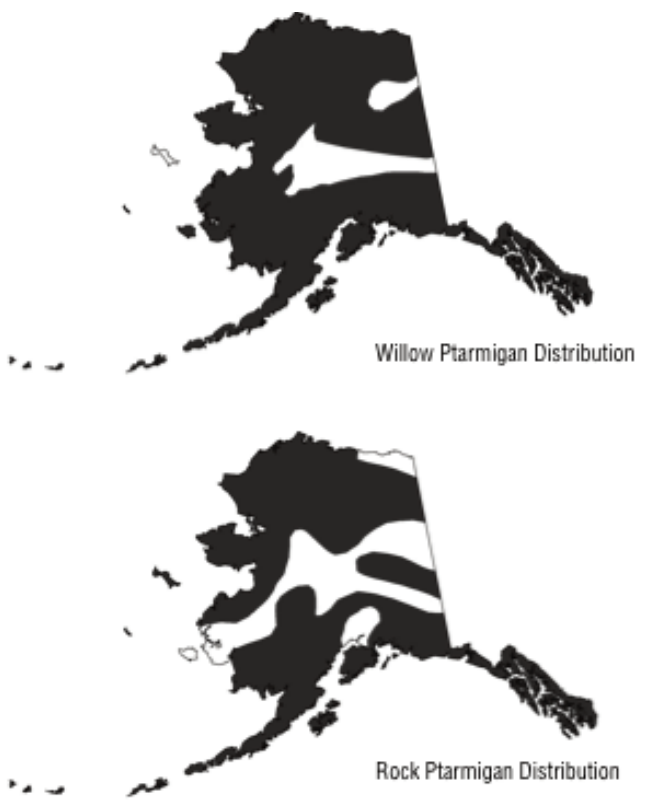

- Ptarmigan presence

- Ptarmigan absence

Figure 2. Distribution of Willow and Rock Ptarmigan occurrence in Alaska digitized from Hannon et al. (1998) and Montgomerie and Holder (2008), respectively. Presence and absence points were randomly distributed inside and outside of each species' distribution. by field biologist during 1972-2007. We did not include 41 nests used by Booms et al. (2009) from Denali National Park because locations of these nests were not provided. However, to our knowledge, our dataset is the largest collection of historical Gyrfalcon nest locations distributed across the state of Alaska. We used these historical nest sites $(n=414)$ as presence points (Figure 1). For absence data, we used pseudo-absence points (Engler et al. 2004) distributed randomly across Alaska ( $\mathrm{n}=$ $10,000)$. For ptarmigan training data, we used hand-digitized distribution maps for Rock and Willow Ptarmigan from Hannon et al. (1998) and Montgomerie and Holder (2008) (Figure 2 ). We randomly assigned presence points within the mapped distribution of each ptarmigan species $(n=7720)$. Likewise, we randomly distributed points outside their mapped distributions in Alaska and used these as absence points $(\mathrm{n}=2280)$. All presence and absence (ptarmigan) or pseudo-absence (Gyrfalcon) points were compiled and overlain with the following predictor variables in Hawth's tools: mean June and December temperature $\left(\mathrm{C}^{\circ}\right)$, mean June and December precipitation amount $(\mathrm{cm})$ (see below), elevation (USGS 1997), and subsurface geology (Beikman 1980) for use as inputs into Random Forest algorithm following Booms et al. (2009) and Cushman and Huettmann (2010).

Future mean June and December temperature and precipitation data were derived from the United Nations IPCC A1B scenario predictions, which were downscaled to the State of Alaska by the Scenarios Network for Alaska Planning (SNAP). The IPCC's A1B scenario projections assumed moderate changes in carbon emission. We averaged mean June and December temperatures and precipitation amounts by decade for the time steps of 2009, 2039, 2069, and 2099. For the time steps of 1916, 1946, 1976, and 2006, we used publicly available Climate Research Unit (CRU) (2010) mean June and December temperatures and precipitation amounts and averaged each decade to backwards-model past distributions of the funda- 
mental niche of these species (1900-2006). To smooth out anomalous local variability in the spatial prediction maps within the predictor layers used as inputs to the model, we followed Booms et al. (2009) using an Inverse Distance Weighting (IDW) interpolation to bring the lattice into 5-km grid cells. The pre-processing of the time-series climate data thus included smoothing in both space and time.

Modeling Approach.-We used the Random Forests (RF) algorithm (Breiman 2001) for predictions of species presence in time and space. This algorithm is widely used in data mining and machine learning (Cushman and Huettmann 2010), and was previously used in Alaska for forecasting SNAP climate data with biodiversity and biome data (Murphy et al. 2010).

Once the training data were prepared to be run through the algorithm, the past and future temperature and precipitation data were attached to $5-\mathrm{km}$ equidistant grid points covering the entire State of Alaska. These point grids were subsequently run through the rule set generated by training the RF model with the presence/absence points and stored in an RF grove file. The individual point grids with temperature and precipitation information for each time-step being analyzed were then applied to the trained model. RF then provided the distribution of the species presence/absence based on the climate information specific to the time step. These output maps were then brought into GIS, and further analyses were performed to quantify the degree of change through time for each of the three species being studied. To assess how temperature has changed at actual nest locations across time, we extracted temperature data from each nest location at each time step using smoothed CRU historical weather data and SNAP future predictions.

We assessed the performance of the models by modeling the species' distributions backwards in time and also by internal re-sampling of data to generate area-under-the-curve (AUC) estimates. Modeling backwards is used as a means to assess the performance of forward-modeling (Wickert et al.2010) by allowing predictions and historical data (truth) to be compared qualitatively or quantitatively. Because rigorous distribution maps of ptarmigan and Gyrfalcons in Alaska during the past 100 years were, to our knowledge, unavailable, we used backwardsmodeling to assess only qualitative accuracy. This approach has been used by others for climate change, impact assessments, and cumulative impact studies, and for being pro-active before damages occur (Nielsen et al. 2008, Huettmann and Gottschalk 2010). We calculated AUC estimates in the receiver operating curve (ROC) plots for all models using 2006 and 2009 training data. Analysis was conducted with program AUC_ROC using default program settings (Schroeder 2008). We considered that AUC scores of $<0.7$ indicated low model accuracy, 0.7-0.9 moderate accuracy, and $>0.9$ high accuracy (Swets 1988). The primary challenges with these approaches are that machine-learning models are still sometimes distrusted by the wildlife management discipline, and model results lack an undisputed measure of true accuracy (Huettmann and Gottschalk 2010).

\section{RESUlTS}

The predicted distribution of each species' fundamental niche generally decreased in spatial extent, connectivity, and overlap across time (Figures 3-5). Models predicted that the geographic area over which the Gyrfalcon, Rock Ptarmigan, and Willow Ptarmigan fundamental niches are predicted to occur declined by $60 \%$, $40 \%$, and $20 \%$, respectively. An inverse relationship between increasing mean June temperature and total area of predicted distribution was present for all three species (Figure 6). The amount of predicted spatial overlap between Gyrfalcons and both Willow and Rock Ptarmigan decreased over time from approximately $95 \%$ and $85 \%$, to $75 \%$ and $45 \%$, respectively (Figure 7). Mean June temperature at known Gyrfalcon nest sites in Alaska increased in the past by $2.3^{\circ} \mathrm{C}$ from $7.7^{\circ}$ to $9.7^{\circ} \mathrm{C}$ and is predicted to increase an additional $2.4^{\circ} \mathrm{C}$ by 2099 
Figure 3. Time series of predicted distributions of the Gyrfalcon's fundamental niche in Alaska across 200 years. Maps of predictions in the left column came from models that used historical CRU climate data; maps in the right column came from models using downscaled IPCC A1B climate predictions.

- Predicted presence

- Predicted absence
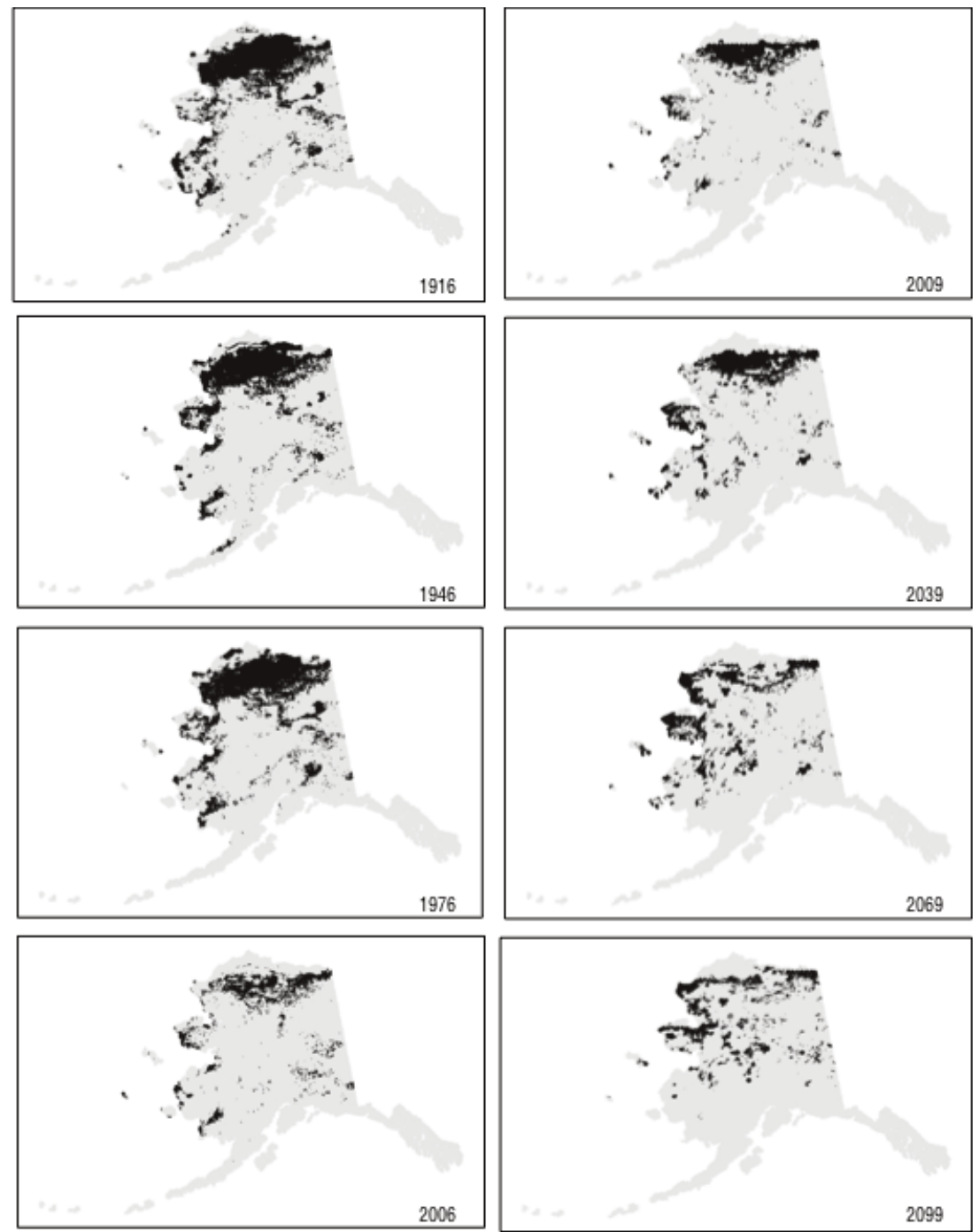

(Figure 8). The area-under-the-curve (AUC) estimate in the receiver operating characteristic (ROC) varied between 0.91-0.99 across all models, suggesting high model accuracy.

\section{Discussion}

General Results. - Our models predicted that the fundamental niches of Gyrfalcons and ptarmigan will contract and have contracted in the past as Alaska's climate has warmed. For all three species, the total area over which fundamental niches were predicted to occur generally decreased as temperature warmed across time. The percent of spatial overlap between Gyrfalcon and ptarmigan fundamental niches also declined. Hence, it is reasonable to expect that the abundance and distribution of these species will likely decline/decrease as temperatures rise in Alaska unless the species alter their fundamental niches to adapt to the documented and predicted rapid warming in Alaska. Considering that sea ice, climate, and cumulative impact models provided by A1B scenarios appear to be underestimates (Stroeve et al. 2007, Meltofte et al. 2008), our similarlybased conclusions may likewise be underestimates of climate change effects. 

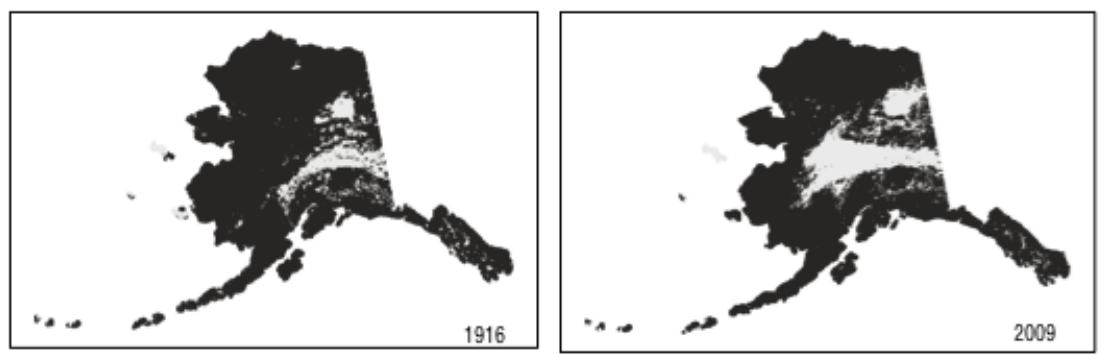

Figure 4. Time

series of predicted

distributions of the

Willow Ptarmigan's

fundamental niche in

Alaska across 200

years. Maps of

predictions in the left

column came from
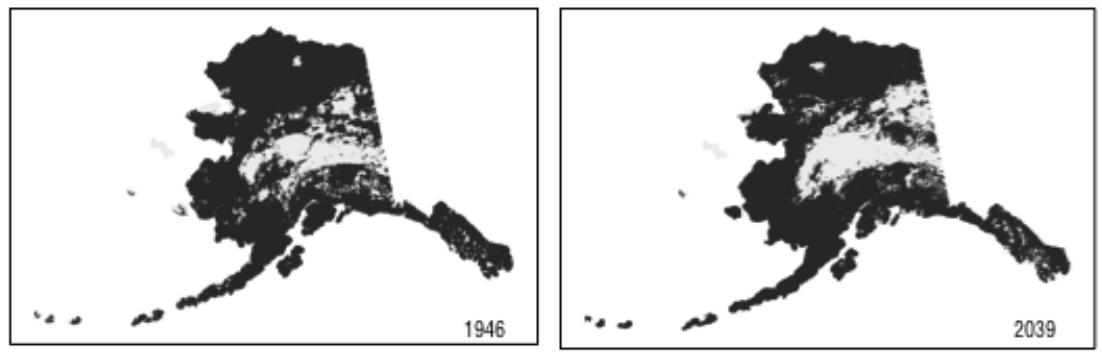

models that used

historical CRU climate

data; maps in the right

column came from

models using

downscaled IPCC A1B

climate predictions.
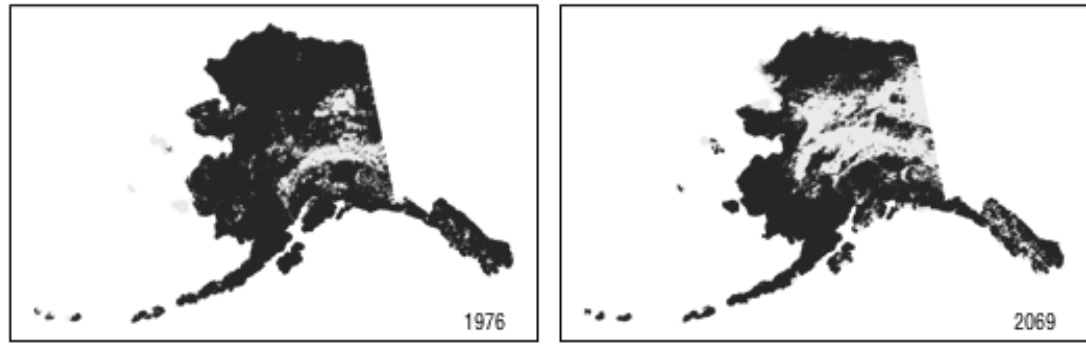

- Predicted presence

- Predicted absence
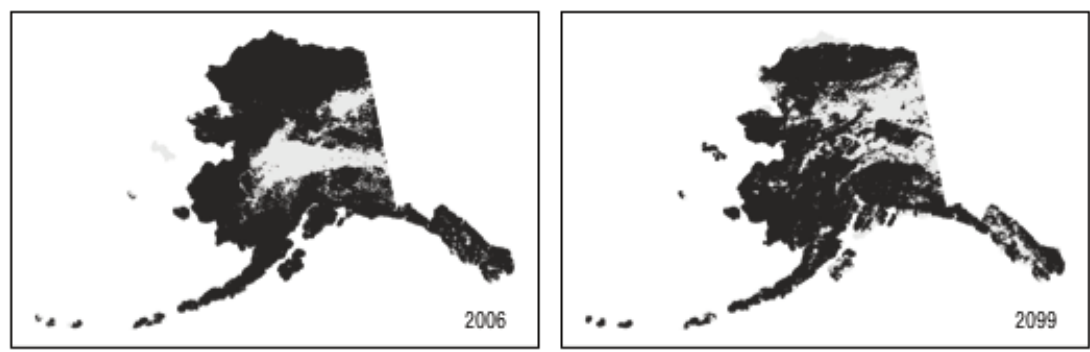

Broad Conclusions.- The models support the following broad conclusions: 1) The spatial extent of the fundamental niche of each of the three species will contract in Alaska. This conclusion is supported by our backward-modeling of historical data and the replication of this trend in each of the three species. Though we do not know how the species will respond to these contractions, we speculate that their distribution and abundance will decline, along with other components of the ecosystem on which they currently depend, as temperatures warm. 2) The amount of spatial overlap of the
Gyrfalcon's and ptarmigan's fundamental niche will decline. Again, this is supported by trends in historical temperature data and by replicated results in both ptarmigan species. How the decline in spatial overlap will specifically affect Alaska's Gyrfalcon population is currently unknown, but at minimum, it will present a challenge to at least some of Alaska's Gyrfalcons. 3) The spatial extent of the fundamental niche of each species will become more heterogeneous and discontinuous in the future. This conclusion is also supported by backward- and forward-modeling and the associ- 
Figure 5. Time series of predicted distributions of the Rock Ptarmigan's fundamental niche in Alaska across 200 years. Maps of predictions in the left column came from models that used historical CRU climate data; maps in the right column came from models using downscaled IPCC A1B climate predictions.
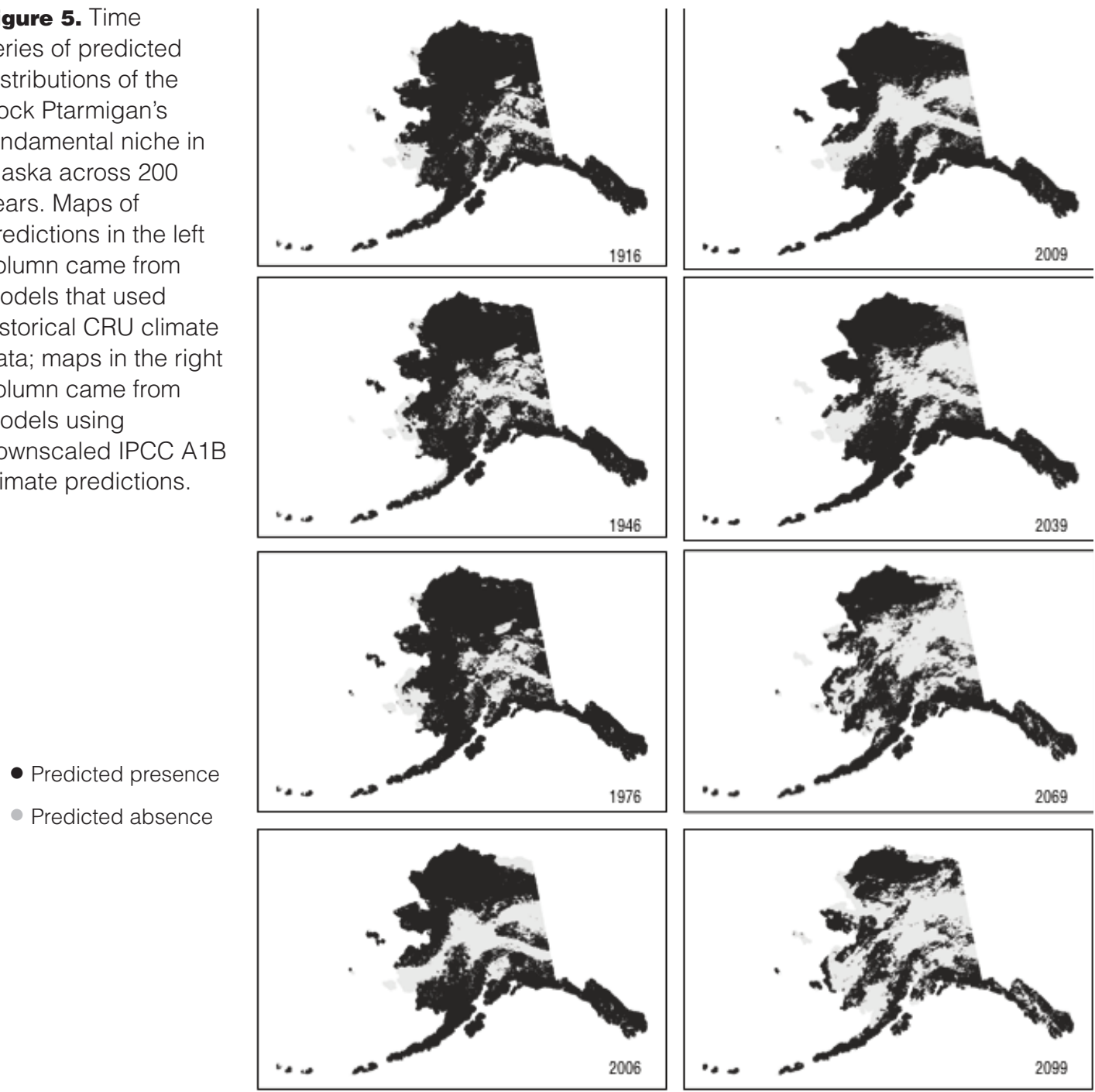

ated distribution maps of each species. In each case, our models predicted that the distribution of the fundamental niche will become more scattered and discontinuous. This trend is least apparent in results from Willow Ptarmigan models, possibly because their niche is broader than that of the Rock Ptarmigan or Gyrfalcon. 4) Based on historical nest and climate data, the mean June temperature has increased by an average of $2.3^{\circ} \mathrm{C}$ at known Gyrfalcon nest sites. Hence, Alaska's Gyrfalcons are already dealing with rising temperatures, though how they are coping, adapting, or failing to adapt to these changes in Alaska is yet unknown.

Interpretation, Accuracy, and Broader Applications. - This model projects only basic, gross trends and should be treated with caution. Our work has followed best practices with the data available and science methodologies used to quantify predictive probability (as outlined in Huettmann and Gottschalk 2010). Predictions and conclusions were formulated from the best available inputs and knowledge of fundamental niches, but admittedly, the 


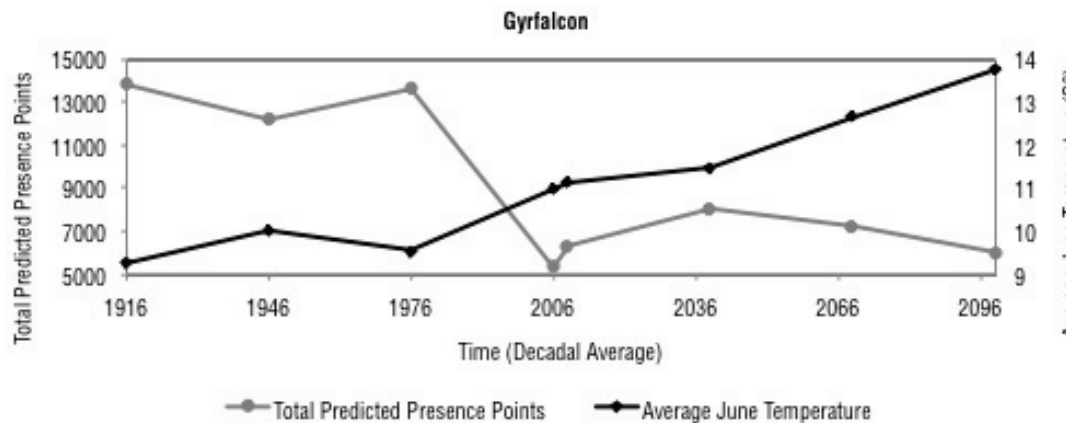

Figure 6. Graphs

displaying the relationship between changes in mean June temperature and total number of predicted presence points for three species in Alaska over time.
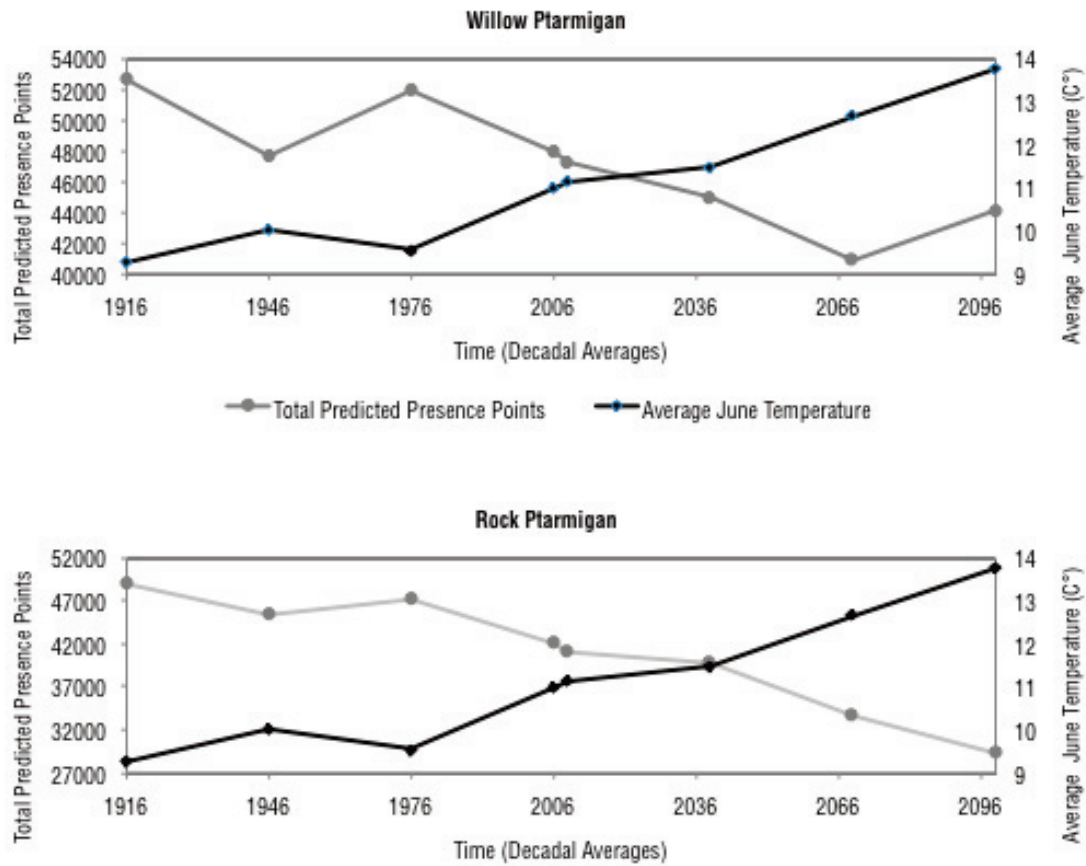

- Total Predicted Presence Points $\rightarrow$ Average June Temperature

models are oversimplifications of very complex systems. Whereas confounding variables and complexities will doubtlessly play important roles in the ultimate distribution and abundance of these species, we have no reason to believe that the basic trends discovered here are grossly inaccurate.

We emphasize that our model is driven by temperature and precipitation change in regionalized, downscaled IPCC scenario data and CRU historic temperature and precipitation reconstructions. Following Zuckerberg et al. (2010), all data layers (except for sensitive raptor nest locations (Booms et al. 2009)), metadata, and predictions used in the publication are available to the global public to access online. As these data and the overall understanding of the effects of temperature and precipitation on species distributions on a landscape are improved, these species models can be changed to incorporate new, better understood inputs. 
Figure 7. Graphs displaying change in the percent of overlapping predicted presence points of Gyrfalcons and Willow and Rock Ptarmigan in Alaska across 200 years.
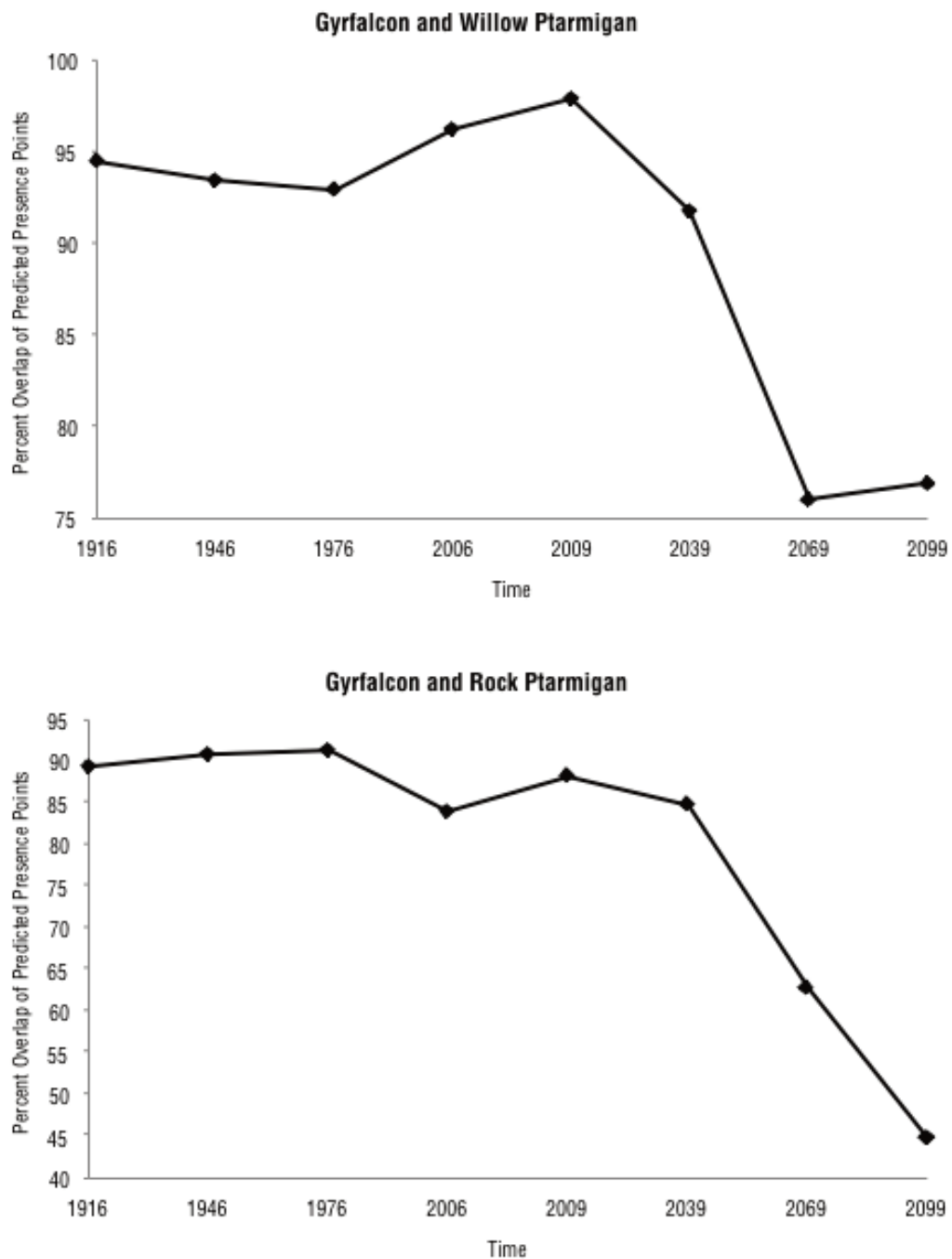

Although we predicted the distribution of fundamental niches spatially, the actual distribution of Gyrfalcons and ptarmigan will be informed by additional variables from their complex realized niche. It is likely the realized niches will be more restricted than the fundamental niches predicted here unless the species are able to rapidly adapt to new conditions and hence, alter their realized niches. Given the pace of climate change relative to the geologic time over which evolution has occurred, however, we speculate that it is unlikely that these species will adapt rapidly enough to respond to climate change. Further, additional ecological impacts such as disease, invasive species, and human encroachment will likely reduce these species' capacity to adapt to rapid climate change. For example, northward expansion or ecological shifts of diseases and parasites facilitated by warming climates (e.g., Hueffer et al. 2011) likely pose significant confounding risks to Gyrfalcons in particular, which are known for their susceptibility to numerous diseases in lower latitudes. 


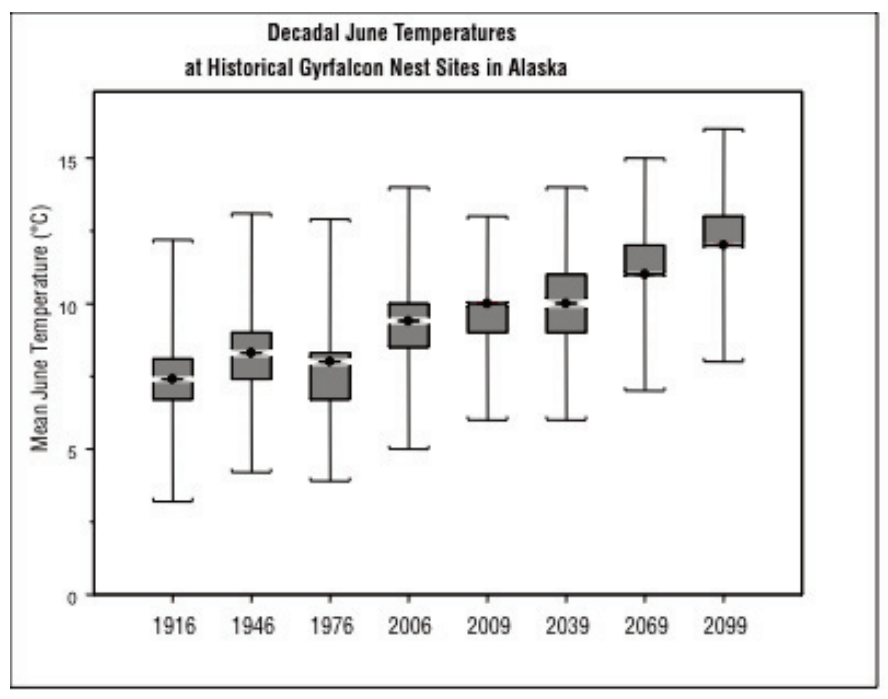

Figure 8. Changes in mean June temperatures at 414 historical Gyrfalcon nest sites in Alaska across 200 years. Estimates from 1916-2006 were derived from interpolated historical climate data (CRU) and are actual data rather than predictions. Estimates from 2009 onward were predictions derived from downscaled IPCC A1B climate predictions.

Climate warming will fundamentally alter ecosystems in Alaska, likely resulting in new species and habitat assemblages (Stralberg et al. 2009, Murphy et al. 2010). For example, Selås et al. (2010) found that ptarmigan reproduction was negatively correlated with the preceding two summers' temperatures, and that this relationship was likely mediated by climate-induced responses at lower trophic levels. Hence, response mechanisms to climate change are likely complex and highly interrelated. Such interactions and animal responses are difficult to predict in detail, but here we showed the general trends that should be expected and that are beginning to be documented elsewhere (e.g., Selås et al. 2010). By modeling the basic components of fundamental niches (temperature and precipitation), we have gained some understanding of the outer bounds and drivers of potential shifts in distributions that may be expected to occur.

Our broad conclusions are similar to those found in other areas and with similar methods (Murphy et al. 2010). Other work is currently being done on invasive species and for most of Alaska's terrestrial biodiversity of over 400 species (Gotthardt et al. in prep.). Similar models have been used to predict changes in other birds' distributions in relation to climate change by a number of other researchers (Crick 2004, Lawler et al. 2010). In North America, Hitch and Leberg (2007) documented northward shifts in species distributions, likely in response to climate change. In general, multiple studies and models have shown changing species distributions likely influenced by climate change and a decline in the area of the Arctic biomes; namely on the southern edges (Murphy et al. 2010). This is in line with the gross trends we predicted here for three Arctic species.

It is also useful to focus on historical data (backwards-modeling) to assess if the forward predictions are reasonable. Again, in all three cases, the basic trend in extent, heterogeneity, and spatial overlap of the predicted fundamental niches are apparent in the historical data during a time in which Alaska's statewide mean annual temperature rose by $1.6^{\circ} \mathrm{C}$ (Alaska Climate Research Center 2010). Further, a short period of apparent cooling evident in CRU data between 1946 and 1976 was reflected in a plateau or temporary increase in the extent of niche distributions. This brief upward trend is visible throughout our models and provides additional qualitative evidence 
that the gross predicted trends observed are reasonable. Lastly, all models had AUC scores $>0.91$, suggesting high model accuracy as gauged by internal assessment (Huettmann and Gottschalk 2010). Hence, we found no evidence to suggest that our models were grossly inaccurate or provide contradictory results.

Finally, it should be noted that Gyrfalcons, ptarmigan, and their habitats are not just affected by climate locally in Alaska. Our data are based on global climate models, and our results should be applicable and testable across the circumpolar Arctic and subarctic north, keeping in mind, however, that species may respond differently in differing climatic conditions.

Management Implications.-Our work demonstrates the value of archiving, collating, and sharing raptor nest location data to maximize the return from such data (Zuckerberg et al. 2010). Because poaching of raptors occurs in some areas, modelers need to be sensitive to real conservation concerns in the field regarding public access to some data types. However, careful sharing of sensitive data, as we demonstrated here in a modeling framework, is important to long-term conservation assessments.

Gyrfalcon and ptarmigan distributions are linked in the food web and are an integral part of a unique ecosystem that is being affected by climate change and other landscape-level changes. Here we have shown for Alaska that increasing temperatures are likely to alter the distribution of the fundamental niches of three Arctic species by decreasing their spatial extent, overlap, and continuity. These alterations will likely influence important ecological and biological processes such as dispersal, genetic diversity, and predator-prey dynamics, and may have cascading effects on other species, communities, and systems. For adaptive management, we propose to test these models further and to make such spatial models and their predictions an inherent part of the management and legal procedures used to address conservation in the world of rapid climate change.

\section{ACKNOWLedgments}

This research was possible because of the significant investment of field effort, money, time, personal interest, and dedication to raptor surveys conducted by a handful of dedicated biologists. We thank T. Swem, R. Ritchie, B. McCaffery, T. Cade, C. White, and others for their tireless dedication to surveying breeding raptors in Alaska and making their data available for this work. Other great efforts came from the IPY team including D. Carlson, the SNAP team, and the EWHALE lab. We also thank G. Hunt for an insightful revision of the original manuscript. FH wishes to acknowledge the great synergies and spirits that come with progressive open access data and modeling work in time and space. This project was funded by the Alaska Department of Fish and Game Wildlife Diversity Program through the federal State Wildlife Grant program and the EWHALE lab. This is EWHALE lab publication no. 103.

\section{Literature Cited}

Alaska Climate Research Center. 2010. Online data. Available at http://climate.gi. alaska.edu/index.html

BeIKMAn, H. M. 1980. Geologic map of Alaska. US Geological Survey Special Publication no. SG0002-1T and SG00022T, Washington, DC, USA.

Booms, T. L., T. J. CADE, AND N. J. Clum. 2008. Gyrfalcon (Falco rusticolus). In A. Poole (Ed.). The Birds of North America Online. Ithaca: Cornell Lab of Ornithology. Retrieved from The Birds of North America Online database: http://bna.birds.cornell. edu/bna/species/114

Booms, T., F. HuettMann, AND P. SchempF. 2009. Gyrfalcon nest distribution in Alaska based on a predictive GIS model. Polar Biology 33:347-358. 
Breiman, L. 2001. Random forests. Machine Learning 45:5-32.

Chapin, F. S., G. P. Kofinas, and C. Folke. 2009. Principles of Ecosystem Stewardship: Resilience-based Natural Resource Management in a Changing World. Springer, New York, USA.

Climate Research Unit. 2010. www.cru.uea. ac.uk/cur/data

CRICK, H. Q. P. 2004. The impact of climate change on birds. Ibis 146:48-56.

Cushman, S., And F. Huettmann. 2010. Spatial Complexity, Informatics and Wildlife Conservation. Springer, Tokyo, Japan.

Drew, C. A., Y. Wiersma, AND F. HuetTMANn. 2010. Predictive Species and Habitat Modeling in Landscape Ecology. Springer, New York, USA.

Dublin, R., AND M. TARAs. 2005. The Grouse and Ptarmigan of Alaska. Alaska Department of Fish and Game, Juneau, Alaska, USA.

ENGLER, R., A. GUISAN, AND L. REChSTEINER. 2004. An improved approach for predicting the distribution of rare and endangered species from occurrence and pseudoabsence data. Journal of Applied Ecology 41:263-274.

Glavin, T. 2000. The Last Great Sea: A Voyage Through the Human and Natural History of the North Pacific Ocean. Greystone Books, Vancouver, British Columbia, Canada.

Hannon, S. J., P. K. EAson, AND K. Martin. 1998. Willow Ptarmigan (Lagopus lagopus). In A. Poole (Ed.). The Birds of North America Online. Ithaca: Cornell Lab of Ornithology. Retrieved from The Birds of North America Online database:http://bna. birds.cornell.edu/bna/species/369

Hinzman, L. D., N. D. Bettez, W. R. Bolton, F. S. Chapin III, M. B. Dyurgerov, C. L. Fastie, B. Griffith, R. D. Hollister, A. Hope, H. P. Huntington, A. M. Jensen, G. J. Jia, T. Jorgenson, D. L. Kane, D. R. Klein, G. Kofinas, A. H. LynCh, A. H. Lloyd, A. D. McGuire, F. E. Nelson, M. Nolan, W. C. Oechel, T. E. Osterkamp,
C. H. Racine, V. E. Romanovsky, R. S. Stone, D. A. Stow, M. Sturm, C. E. Tweedie, G. L. Vourlitis, M. D. Walker, D. A.Walker, P. J. Webber, J. Welker, K. S. WINKER, AND K. YOSHIKAWA. 2005. Evidence and implications of recent climate change in northern Alaska and other arctic regions. Climatic Change 72:251-298.

Hitch, A. T., AND P. L. Leberg. 2007. Breeding distributions of North American bird species moving north as a result of climate change. Conservation Biology 21:534-539. Hutchinson, G. E. 1957. A Treatise on Limnology. Wiley \& Sons, New York, USA. HuEFFER, K., T. M. O'HARA, AND E. H. FollMANN. 2011. Adaptation of mammalian host-pathogen interactions in a changing Arctic environment. Acta Veterinaria Scandinavica 53:17.

Huettmann, F., and T. Gottschalk. 2010. Simplicity, model fit, complexity and uncertainty in spatial prediction models applied over time: We are quite sure, aren't we? Pages 189-208 in A. C. Drew, Y. Wiersma, and F. Huettmann (Eds.). Predictive Species and Habitat Modeling in Landscape Ecology. Springer, New York, USA.

Krebs, C. J., S. Boutin, AND R. Boonstra. 2001. Ecosystem Dynamics of the Boreal Forest: The Kluane Project. Oxford University Press, New York, USA.

Lawler, J. J., S. L. Schafer, D. White, P. Kareiva, E. P. Maurer, A. R. Blaustein, AND P. BARTLEIN. 2009. Projected climateinduced faunal change in the Western Hemisphere. Ecology 90:588-597.

LotKA, A. J. 1925. Elements of Physical Biology. Williams \& Wilkins Co., Baltimore, Maryland, USA.

Martin, P. D., J. L. Jenkins, F. J. Adams, M. T. Jorgenson, A. C. Matz, D. C. PAYer, P. E. Reynolds, A. C. Tidwell, and J. R. ZELENAK. 2009. Wildlife response to environmental arctic change: Predicting future habitats of Arctic Alaska. Report of the Wildlife Response to Environmental Arctic Change (WildREACH): Predicting Future Habitats of Arctic Alaska Workshop, 17-18 
November 2008. US Fish and Wildlife Service, Fairbanks, Alaska, USA.

Meltofte, H., T. R. Christensen, B. ElberLING, M. C. FORCHHAMMER, AND M. RASCH. 2008. High-Arctic Ecosystem Dynamics in a Changing Climate: Ten years of monitoring and research at Zackenberg Research Station, Northeast Greenland. Advances in Ecological Research, vol. 40. Academic Press, USA.

Montgomerie, R., ANd K. Holder. 2008. Rock Ptarmigan (Lagopus muta). In A. Poole (Ed.). The Birds of North America Online. Ithaca: Cornell Lab of Ornithology. Retrieved from The Birds of North America Online database: http://bna.birds.cornell. edu/bna/species/051

Murphy, K., F. Huettmann, N. Fresco, And J. Morton. 2010. Connecting Alaska landscapes into the future. US Fish and Wildlife Service and the University of Alaska Report.http://www.snap.uaf.edu/downloads/ connecting-alaska-landscapes-future

Nielsen, S. E., G. B. Stenhouse, H. L. Beyer, F. Huettmann, And M. S. Boyce. 2008. Can natural disturbance-based forestry rescue a declining population of Grizzly Bears? Biological Conservation 141:2193-2207.

Peterson, A. T., J. Soberón, AND V. SÁnChEZCoRdero. 1999. Conservatism of ecological niches in evolutionary time. Science 285:1265-1267.

Schroeder, B. 2008. Program AUC_ROC. http://brandenburg.geoecology.unipotsdam. de/users/schroeder/download.html.

Selås, V., G. A. Sonerud, E. Framstad, J. A. KÅlÅs, S. Kobro, H. B. Pedersen, T. K. SPIDS $\varnothing$, AND Ø. WIIG. 2010. Climate change in Norway: Warm summers limit grouse reproduction. Population Ecology 53: 361-371. http://dx.doi.org/10.1007/s10144010-0255-0
Stralberg, D., D. Jongsomit, C. A. Howell, M. A. Snyder, J. D. Alexander, J. A. WIENS, AND T. L. RoOT. 2009. Re-shuffling of species with climate disruption: A noanalog future for California birds? PLoS ONE 4(9):e6825.

Stroeve, J., M. M. Holland, W. Meier, T. Scambos, AND M. SerReze. 2007. Arctic sea ice decline: Faster than forecast. Geophysical Research Letters 34:L09501.

SwETS, J. A. 1988. Measuring the accuracy of diagnostic systems. Science 240:1285-1293.

Symon, C., L. Arris, AND B. Heal. 2005. Arctic Climate Impact Assessment. Cambridge University Press, New York, USA.

Turner, M. G., D. B. Tinker, S. E. Gergel, AND F. S. CHAPIN III. 2002. Landscape disturbance: Location, pattern, and dynamics. Pages 147-165 in S. E. Gergel and M. G. Turner (Eds.). Learning Landscape Ecology: A Practical Guide to Concepts and Techniques. Springer Publishers, New York, USA.

US GEOlogical SuRvey. 1997. Alaska 300 m digital elevation model. US Geological Survey Alaska Field Office, Anchorage, Alaska.

Watson, J. 2010. The Golden Eagle. Poyser Monographs, $2^{\text {nd }}$ ed. T. \& A. D. Poyser Publisher, London, UK.

Wickert, C., D. WAllschlaeger, AND F. Huettmann. 2010. Spatially predictive habitat modeling of a White Stork (Ciconia ciconia) population in former East Prussia in 1939. Open Ornithology 3:1-12.

ZuCKerberg, B., F. HuetTMANN, AND J. Frair. 2010. Proper data management as a scientific foundation for reliable species distribution modeling. In A. C. Drew, Y. Wiersma, and F. Huettmann (Eds.). Predictive Species and Habitat Modeling in Landscape Ecology. Springer, New York, USA. 